\title{
DEVELOPING GEOPOLYMER COMPOSITES USING DRY MIXING TECHNIQUE
}

Sood, D., Krisht, J. and Hossain, K.M.A.

Department of Civil Engineering, Ryerson University

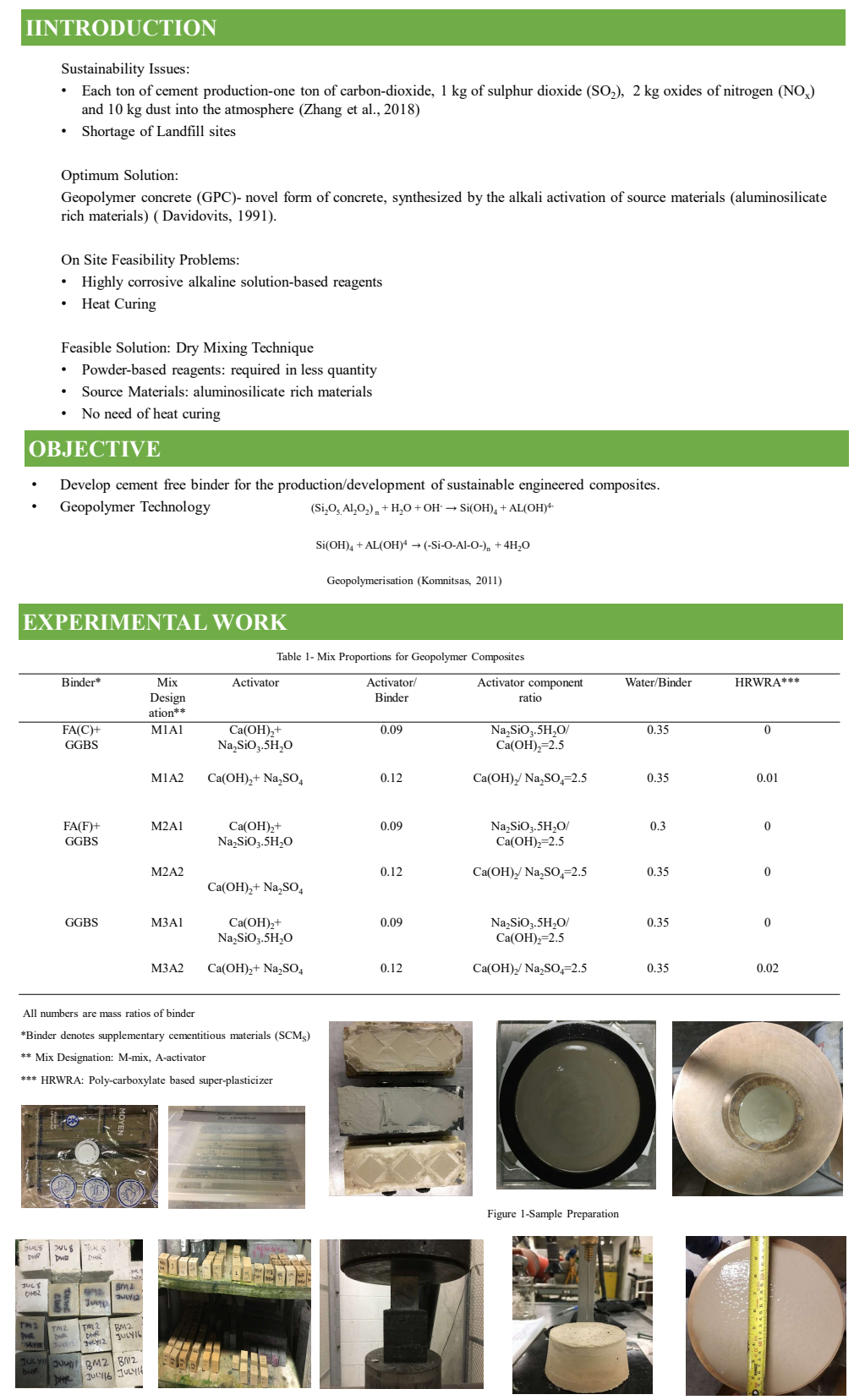

(1)

\section{RESULTS AND CONCLUSIONS}
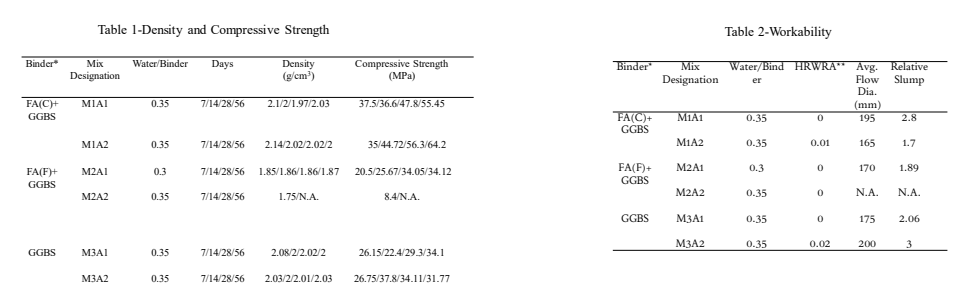

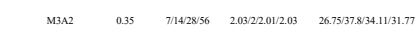
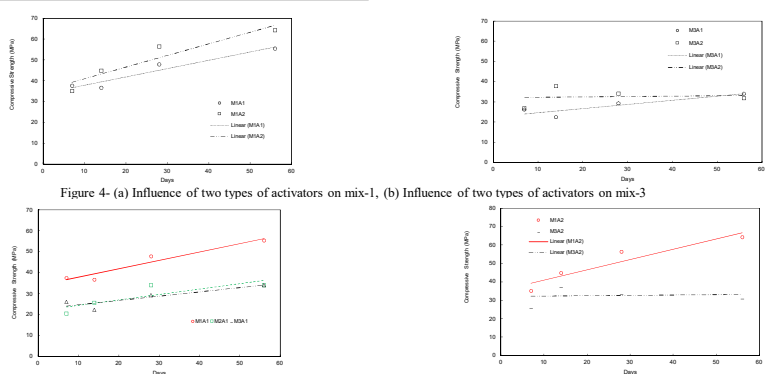

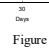

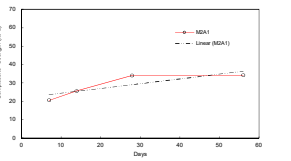

Figure 6-Compressive strenght for nix (M2A)
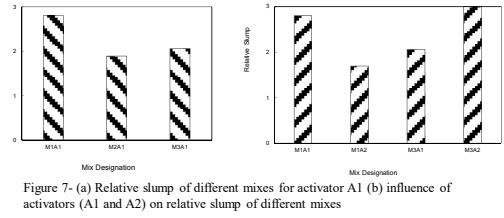

- The mix combination (M1A2) achieved the highest compressive strength of $64.2 \mathrm{MPa}$ at 56 days.

- The mix M1A1 exhibited a comparable compressive strength of $55.45 \mathrm{MPa}$ at 56 days and higher slump flow than mix M1A2. - The initial and final setting time of the mix MIA1 was determined to be as 119 minutes and 259 minutes respectively.

M1A1 was designated as the best performing mix based on slump flow and compressive strength characteristic.

\section{REFERENCES}

Zhang, J., Zhang, P., Zheng, Y. and Wang, K. 2018. A review on properties of fresh and hardened geopolymer mortar. Composites Davidovits, J. 1991. Geopolymers. Journal of Thermal Analysis, 37(8): 1633-1656.

Li, V. C., \& Kanda, T. (1998). Engineered Cementitious Composites for structural applications. Journal of Materials in Civil Engineering, 10(2), 66-69.

Komnitsas, K. A. (2011) 'Potential of geopolymer technology towards green buildings and sustainable cities', Procedia Standard Test Method for Compressive Strength of Hydraulic Cement Mortars (Using 2-in. or [50-mm] Cube Specimens)1'

(152/C1437

Designation: C191 - 18a Standard Test Methods for Time of Setting of Hydraulic Cement by Vicat Needle 1' (2018). do

\section{ACKNOWLEDGEMENTS}

- CRH Canada
- ATCO Power

ATCO Power

- NSERC 